\title{
ПРИБОРОСТРОЕНИЕ
}

УДК 621.396.962.21

Дзюба А.П.

ПЕРСПЕКТИВЫ РАЗВИТИЯ ФАЗИРОВАННЫХ АНТЕННЫХ РЕШЕТОК

Dzuba A.P.

\section{PROSPECTS FOR THE DEVELOPMENT OF PHASED ANTENNA ARRAYS}

В данной статье рассмотрены основные достижения в разработке фазированных антенных решеток (далее по тексту - ФАР) в последнее десятилетие. Приведен обзор наиболее известных систем на базе ФАР и ФАР построенных на основе новой технологии ММІС - ФАР в радиолокачионных станциях, ФАР для управления лазерными и оптическими лучами. Предложены варианты построения ФАР: сегнетоэлектрическая антенная решетка; плазменная антенна с электронным сканированием; отражательная решетка на 100-мм полупроводниковых пластинах; широкополосные антенные решетки с разделением апертуры; антенные решетки с иифровым формированием диаграммы направленности.

Ключевые слова: фазированная антенная решетка, радиолокационные станции, технология ММІС, антенная решетка с ичифровым управлением.

This article describes the main achievements in the development of phased antenna arrays (par) in the past decade. Provides an overview of the most famous systems based on the PAR and PAR based on MMIC technology - PAR in radar stations, PAR to control the laser and optical beams. The existing options for the design of the PAR:ferroelectric antenna array; plasma antenna with electronic scanning; reflective grating on 100-mm semiconductor wafers; wideband antenna arrays with aperture; antenna arrays with digital beam forming.

Key words: phased array antenna, radar stations, MMIC technology, antenna array with digital control.

\section{Введение}

Фазированные антенные решетки (ФАР) прошли долгий научно-практический путь развития. Первые ФАР были созданы более 35 лет назад и с тех пор находят широкое применение в различных радиоэлектронных системах. Интерес к ним не ослабевает и сегодня. Об этом свидетельствуют непрекращающиеся поиски новых, эффективных решений, опирающихся на самые современные технологии и способных существенно расширить сферы применения ФАР.

Развитие теории и техники ФАР в настоящее время идет по следующим наиболее важным направлениям:

1) использование в перспективных радиотехнических устройствах активных ФАР с большим числом элементов новых типов;

2) разработка и внедрение новых методов построения ФАР с раскрывом больших размеров, например, проект глобальный Радиотелескоп на основе неэквидистантной ФАР, в состав которой входят остронаправленные антенны, расположенные на одном из полушарий Земли;

3) разработка и совершенствование радиотехнических элементов и методов, позволяющих ослабить взаимовлияния между элементами ФАР;

4) дальнейшее развитие методов синтеза ФАР и автоматизации их проектирования; 
5) дальнейшая разработка и внедрение методов обработки принятой элементами ФАР информации, обеспечивающих, например, управление формой ДН (адаптивные ФАР) и автоматическое фазирование элементов ФАР (самофазирующиеся ФАР):

6) разработка методов управления независимым движением отдельных лучей в многолучевых ФАР.

\section{Достижения последних десятилетий}

Выдающиеся достижения в разработке ФАР за последние десятилетия обеспечили им широкое внедрение в различные радиотехнические системы и комплексы, обеспечивающие обнаружение и сопровождение как воздушных, так и наземных целей. Образцами таких систем можно назвать следующие:

- зенитно-ракетный комплекс Patriot (США);

- бортовая система дальнего обнаружения целей AEGIS (CША);

- радиолокационная станция (РЛС) обнаружения артиллерийского и минометного огня TPQ-37 (США);

- РЛС GPN-22 (СШA);

- РЛС Flap Lid (Россия).

\section{Обзор характеристик наиболее известных систем с ФАР}

Первой РЛС с твердотельными приемопередающиими элементами в антенной решетке была станция PAVE PAWS, работающая в УВЧ-диапазоне. ФАР этой РЛС имеет два раскрыва по 1792 приемопередающих модуля с выходной мощностью 330 Вт.

PЛС обнаружения огневых позиций противника ARTHUR (Швеция), с передатчиком на ЛБВ работает в С-диапазоне волн (3,9-6,2 ГГц).

На вооружении ВВС Швеции также состоит самолетная радиолокационная система дальнего обнаружения Erieye S-диапазона волн (1,55-5,2 ГГц), оснащенная твердотельной ФАР, которая размещена по обе стороны надфюзеляжного киля и включает в себя около 200 приемопередающих модулей.

Самолетная радиолокационная система дальнего обнаружения, установленная на истребителе Phalcon израильского производства, содержит четыре твердотельных ФАР. Две из них размещены на крыльях самолета и две - под фюзеляжем в носовой и хвостовой частях. Каждая ФАР включает в себя около 700 приемопередающих модулей. РЛС работает в L-диапазоне $(0,39-1,55$ ГГц).

Твердотельной активной ФАР оборудован разработанный в Израиле радиолокатор системы обнаружения ракетных установок, действующий в L-диапазоне. Его дальность составляет несколько сотен километров.

Среди последних разработок в этой области, ведущихся в странах ЕC, многофункциональная РЛС с ФАР, предназначенная для установки на корабле. РЛС на передатчике с ЛБВ работает в С-диапазоне волн. Дальность обнаружения целей достигает 180 км. Антенная решетка вращается по азимуту со скоростью 60 об/мин. В угломестной плоскости производится фазовое управление лучом. В создании этой РЛС принимают участие фирмы Alenia (Италия) и Marconi (Великобритания).

Специалистами фирмы Thomson-CSF разработана корабельная РЛС обнаружения воздушных целей Arabel. Станция работает в X-диапазоне и имеет дальность действия около 70 км. ФАР станции вращается по азимуту со скоростью 60 об/мин.

\section{Технология ММІС - новые технологии в развитии ФАР}

\section{ФАР в радиолокационных станциях.}

Огромные возможности для создания активных фазированных решеток открыла технология ММIC (монолитные интегральные схемы СВЧ-диапазона), применение которой значительно снизит стоимость производства твердотельных приемопередающих модулей. Преимущество этой технологии обеспечивает Арсенидгаллиевая основа. К 
примеру: изготовлено свыше 60 тыс. модулей MMIC для оснащения трех PЛC THAAD. За счет отлаженного производства стоимость одного модуля составила менее 1000 долл.

Большие возможности открывает технология ММІС при изготовлении ФАР для самолетных РЛС. Используя технологию ММІС для изготовления ФАР, МО США планирует оснастить активными фазированными антенными решетками бортовые РЛС 424 истребителей F-22. ФАР будет включать в себя примерно 2 тыс. элементов и приемопередающих модулей, выполненных по технологии ММІС. Этой программой предусмотрен выпуск около 1 млн. модулей. Правительство Японии намерено установить активные ФАР на истребителе FSX. Европейский консорциум немецких, французских и английских фирм ведет разработку активной ФАР с элементами, выполненными по технологии MMIC, для многофункциональной бортовой PЛC AMSAR. Шведские специалисты также разрабатывают активную ФАР с применением MMIC-технологии. Все упомянутые станции работают в Х-диапазоне волн.

Активные ФАР, собранные на модулях ММІС, находят применение и в спутниковых системах персональной телефонной связи. (Основные данные о модулях ММІС в спутниковых системах связи, находящихся на сегодня в процессе создания, приведены в табл.3.) Так, на каждом из 66 спутников системы Iridium установлены три антенны, направленные на Землю для панорамного обзора.

Антенна представляет собой активную ФAP L-диапазона, которая содержит примерно 100 приемопередающих модулей и коммугируемых излучающих элементов, выполненных по технологии ММІС. Общее число модулей ММIC в составе Iridium достигает почти 20 тыс. Кстати, проект Iridium - наглядный пример конверсии военных технологий. Так, технология создания космических антенн L-диапазона заимствована из программы создания РЛС космического базирования SBR, над которой работали специалисты ВВС и ВМС США. Специально для этой станции был разработан ММICприемопередающий модуль L-диапазона массой всего 28 г, который стал основой модуля системы Iridium.

Антенные решетки на модулях МMIC находят применение и в высокопроизводительных (со скоростью передачи данных 1 Мбит/с) цифровых коммуникационных системах, предназначенных для связи между компьютерами и для проведения видеоконференций. Пример такой системы - низкоорбитальная спутниковая система Teledesic, в состав которой предположительно войдет 840 спутников. Одна из возможных конфигураций системы Teledesic предполагает установку на одном спугнике 60 передающих ФАР с частотой 20 ГГц и 60 приемных решеток с частотой 30 ГГц. Каждая решетка будет включать в себя примерно 400 приемопередающих модулей и излучающих элементов, изготовленных по технологии ММІС. Разработчики - фирмы Microsoft и McCaw Cellular Communications - планируют использовать в системе около 40 млн. таких модулей и излучающих элементов.

\section{ФАР для управления лазерными и оптическими лучами.}

Разработка антенной решетки, производящей электронное сканирование оптических и лазерных лучей, велась с середины 60-х годов. Несмотря на многие трудности и даже сомнения в принципиальной возможности ее реализации, такая решетка была создана. Ее конструкция представляет собой $\mathrm{N}$ столбцов и $\mathrm{N}$ строк жидкокриталлических фазовращателей, которые соответственно разнесены с интервалом в половину световой волны. Фазовращатели выполнены на двух жидкокристаллических пластинах, на одной стороне которых нанесен прозрачный проводящий слой заземления, а на другой методом фотолитографии сформированы соответственно $\mathrm{N}$ вертикальных и $\mathrm{N}$ горизонтальных полосок из прозрачного проводящего материала. Приложив напряжение между какойлибо проводящей полоской и заземляющим слоем, можно изменять значение диэлектрической постоянной жидкокристаллического фазовращателя, что, в свою очередь, изменяет скорость распространения проходящего через него лазерного или 
оптического сигнала. Пластина со столбцами фазовращателей производит сканирование луча в азимугальной плоскости, а пластина со строками - в угломестной.

\section{Сегнетоэлектрическая антенная решетка.}

Специалисты научно-исследовательской лаборатории ВМС США разработали недорогую фазированную антенную решетку СВЧ-диапазона с аналогичным матричным методом управления лучом, но вместо жидкокристаллических фазовращателей использовали сегнетоэлектрические. Диэлектрические постоянные столбцов и строк фазовращателей зависят от приложенного напряжения. При ступенчатом изменении напряжения формируется фазовый градиент, необходимый для управления лучом по азимуту и углу места. Конструктивно сегнетоэлектрическая антенная решетка состоит из двух линз. Первая линза, состоящая из столбцов сегнетоэлектрических фазовращателей, производит сканирование луча по азимуту. Вторая, повернутая относительно первой на 90 и и состоящая из строк фазовращателей, сканирует луч по углу места. Для правильной работы сегнетоэлектрических линз необходимо, чтобы электрическое поле было линейно поляризовано и его вектор перпендикулярен проводящим пластинам. Таким образом, для линзы, сканирующей луч в азимутальном направлении, требуется сигнал с линейной горизонтальной поляризацией, а для линзы, сканирующей луч в угломестном направлении, - с линейной вертикальной. Поворот плоскости поляризации на 90 о осуществляет среда, размещенная между двумя сегнетоэлектрическими линзами.

\section{Плазменная антенна с электронным сканированием.}

Специалисты научно-исследовательской лаборатории ВМС США работают также над созданием принципиально новой антенной системы, в которой электронное управление лучами осуществляется с помощью плазменного отражателя. Исследования показывают, что плазма при достаточной плотности обладает способностью отражать электромагнитную энергию. Причем чем выше частота облучения, тем большую плотность должна иметь плазма. Концепция построения плазменной антенны показана на рис.4. Плазменный слой создается в вакуумной камере при газовом разряде между анодной пластиной и линейным катодом, который представляет собой линейку элементов определенного адреса на двухкоординатной сетке катода. Изменяя положение линейного катода, можно вращать плазменный слой и тем самым сканировать отраженный луч по азимуту. Сканирование луча по углу места производят изменением наклона плазменного отражателя путем регулирования магнитного поля катушек Гельмгольца. Последние размещены вокруг отражателя так, чтобы не блокировать СВЧ-сигнал. Положением линейного катода и значением магнитной индукции управляет компьютер. Согласно расчетам, точность установки луча в заданном направлении составляет $1-2^{\circ}$, чего, по мнению разработчиков, вполне достаточно. Время переориентации луча - около 10 мкс, однако предварительные испытания показывают, что оно может быть еще меньше. Для образования плазменного слоя в камере достаточно поддерживать вакуум примерно 13 Па. Магнитная индукция должна составлять около 0,02 Тл, ток - порядка 2 А и напряжение - 20 кВ. В 1996 году был сформирован плазменный отражатель размерами 60x60x1 см. Уровень боковых лепестков при этом составил примерно -20 дБ. В 1997 году планировалось создать отражатель диаметром около двух метров. В числе достоинств плазменных антенн - возможность быстрой и точной установки луча, что позволяет одновременно выполнять операции поиска и сопровождения групповых целей, а также формировать разные диаграммы направленности. Кроме того, такие антенны обладают широкой полосой частот, в результате чего один и тот же плазменный отражатель можно использовать с разными облучателями

Созданная плазменная антенна имеет диапазон от 5 до 20 ГГц, который в дальнейшем предполагается расширить до 50 ГГц. В отличие от обычных отражательных антенн, которые существенно повышают эффективную площадь рассеяния локатора при 
облучении его средствами радиоразведки вероятного противника, этот параметр в плазменной антенне невелик.

Отражательная решетка на 100-мм полупроводниковых пластинах.

Успехи технологии ММIC позволяют создавать антенные решетки, интегрированные на полупроводниковых пластинах диаметром 100 мм. Так, специалисты французской фирмы Thomson-CSF ведуг разработку антенны для противоракетного комплекса, которая состоит из двух таких пластин. На одной пластине сформированы дипольные элементы и одноразрядные фазовращатели на ріп-диодах, на второй управляющие схемы. Пластины соединены между собой с помощью бугорковых контактов. Антенна, включающая около 3 тыс. элементов, формирует луч шириной 2о, который может осуществлять сканирование в секторе углов 45o. Рабочая частота антенны -94 ГГц.

Фирма Thomson-CSF при создании антенны RADANT, предназначенной для установки на многоцелевом боевом летательном аппарате, использовала метод сканирования лучей, аналогичный разработанному для сегнетоэлектрической решетки. В антенне RADANT сегнетоэлектрики заменены диодами, которые размещены между проводящими полосками один за другим в направлении распространения волны.

\section{Широкополосные антенные решетки с разделением апертуры.}

Перспективы развития ФАР связывают с увеличением их рабочей полосы. Как полагают специалисты, одна широкополосная ФАР сможет одновременно выполнять несколько функций и работать с несколькими радиоэлектронными средствами. Специалисты Центра вооружения авиации ВМС США совместно с фирмой Техаs Instruments в рамках программы создания усовершенствованной ФАР с разделением апертуры ASAP ведут разработку бортовой ФАР для истребителя-бомбардировщика. Диапазон ее частот будет постоянно охватывать полосу от С- до Ки-диапазона (3,9-17,25 ГГц). В этой полосе будут совместно работать бортовой локатор, пассивные средства радиоэлектронной поддержки, постановщик активных помех и средства связи. Для получения такой широкой полосы в антенной решетке применены щелевые трапецеидальные излучатели, которые к тому же обеспечивают горизонтальную, вертикальную и круговую поляризацию радиоволн. По технологии ММІС создан приемопередающий модуль, который может работать в полосе частот от $\mathrm{C}$ до Ки. Его выходная мощность 2-4 Вт, коэффициент шума 6,5-9 дБ, КПД по мощности 5,5-10\%. Антенные решетки такого типа позволят одновременно использовать отдельные их части для различных бортовых систем - локатора, средств радиоэлектронной поддержки, постановщика активных помех и средств связи. Размер и расположение участков решетки, используемых для каждой функции, могуг изменяться в процессе работы и при необходимости накладываться друг на друга.

\section{Антенные решетки с цифровым формированием диаграммы направленности.}

Метод цифрового формирования диаграммы направленности (ДН) антенной решетки давно привлекает внимание специалистов, поскольку обеспечивает адаптивное управление формой ДН, в частности, формирование провалов («нулей») ДН в направлении источников радиопомех. До недавнего времени метод применялся только в станциях с невысокой частотой обновления данных, в частности, в сонарных системах и загоризонтных РЛС НЧ-диапазона. Например, он используется для формирования приемной ДН в стационарной загоризонтной РЛС фирмы General Electric и в передислоцируемой загоризонтной РЛС фирмы Raytheon. Несмотря на сложные проблемы, связанные с применением метода в РЛС СВЧ-диапазона, где частота обновления данных значительно выше, определенные успехи достигнуты и в этом направлении. 
Так, датская фирма Signaal применила цифровое формирование ДН в антенных системах своих трехкоординатных корабельных РЛC SMART-L и SMART-S, правда, только в режиме приема. Антенна РЛC SMART-L состоит из 24 строк излучателей.

Значительных успехов в разработке методов цифрового формирования ДН добились специалисты Ромской исследовательской лаборатории, выполняющие заказ DARPA. Для проведения исследований была создана антенная решетка С-диапазона, состоящая из 32 столбцов излучателей. Лучи формируются с помощью быстродействующего цифрового формирователя ДН. В его состав входят четыре процессора, которые обрабатывают сигналы по 64 каналам и формируют 4, 8, 16 или 32 независимых луча. Процессоры имеют систолическую архитектуру и обеспечивают выполнение операций умножения и сложения с высокой скоростью. Производительность одного процессора - 5.109 комплексных операций в секунду.

В лаборатории изучается применение методов цифрового диаграммоформирования для коррекции ДН элементов антенной решетки, а также формы ДН всей решетки в случае выхода из строя ее отдельных элементов. Специалисты лаборатории создали также устройство цифрового формирования на базе нейронной вычислительной сети. На фирме Roke Manor Research сконструирована экспериментальная 13-элементная антенная решетка, в которой цифровое формирование происходит как в режиме приема, так и в режиме передачи. Формирование в режиме передачи позволяет ориентировать «нули» ДН в направлении возможной угрозы противорадиолокационных ракет либо высокого уровня помех. Шведские специалисты предложили новый метод цифрового формирования ДН с стробированием сигнала промежуточной частоты. Метод испытан на экспериментальной решетке, работающей в диапазоне 2,8-3,3 ГГц.

Для выполнения операции цифрового формирования сигнал промежугочной частоты 19,35 МГц стробировался с частотой 25,8 МГц. Исследования показали, что такое формирование ДН компенсирует амплитудные и фазовые вариации между элементами, возникающие при работе в широком угловом секторе и в широкой полосе частот. Так, изменение коэффициента усиления в угловом секторе, происходящее из-за взаимного влияния элементов решетки, было снижено с +1 до $+0,1$ дБ, а изменение того же параметра в полосе частот 5 МГц - с 0,5 до 0,05 дБ.

Применение антенных решеток с цифровым формированием ДН не ограничивается стационарными станциями. Недавно были проведены летные испытания бортовой PЛC Lдиапазона с цифровым диаграммо-формирователем, в состав которого входит адаптивный процессор пространственно-временной обработки сигналов STAP. ФАР, состоящая из 11 столбцов излучателей, размешалась вдоль фюзеляжа самолета. Станция обеспечивает подавление помех от 52 до 69 дБ.

\section{Заключение}

Основные научно-технические результаты работ в области антенных систем с электронным управлением лучом могуг быть с успехом применены не только в системах управления вооружением, но и в радиолокации широкого назначения: метеорадарах, авиационных и наземных системах наблюдения и информационного обеспечения, управления воздушным движением, связи и др. Эффективность применения наших технологий для решения этих новых задач определяется не только высокими радиотехническими и массо-габаритными характеристиками и новыми функциональными возможностями, но и низкой себестоимостью изготовления $\mathrm{AC}$, обусловленной комплексом высокопроизводительных технологий и производственных процессов.

Наиболее актуальными проблемами, в настоящее время, являются: повышение эффективности использования в РЛС возможностей электронного управления лучом; точное формирование задач разработчикам нового поколения антенн и радаров по функциональным, эксплуатационным и стоимостным показателям на базе современной военной стратегии. 


\section{Библиографический список:}

1. Устройства СВЧ и антенны. Проектирование фазированных антенных решеток: Уч. Пособие для вузов \.И. Воскресенский, В.И Степаненко. М: Радиотехника, 2003 - 632с.:

2. Цифровое формирование диаграммы направленности в фазированных антенных решетках. Л.Н. Григорьев. М: Радиотехника, 2010. - 144c.

3. Активные фазированные антенные решетки. Под редакцией Д.И. Воскресенского, А.И. Канащенкова. М: Радиотехника, 2004. -488 с

4. http://www.kit-e.ru/articles/sensor/2008_01_41.php

5. http://www.kit-e.ru/articles/wireless/2007_09_164.php 